\title{
A nine-year audit of open-access upper gastrointestinal endoscopic procedures: Results and experience of a single centre
}

\author{
Dean Keren MD, Tova Rainis MD, Edy Stermer MD, Alexandra Lavy MD
}

D Keren, T Rainis, E Stermer, A Lavy. A nine-year audit of open-access upper gastrointestinal endoscopic procedures: Results and experience of a single centre. Can J Gastroenterol 2011;25(2):83-88.

BACKGROUND: The appropriateness and safety of open-access endoscopy are very important issues as its use continues to increase. OBJECTIVE: To present a review of a nine-year experience with open-access upper gastrointestinal endoscopy with respect to indications, diagnostic efficacy, safety and diseases diagnosed.

METHODS: A retrospective, observational case series of all patients who underwent open-access endoscopy between January 2000 and December 2008 was conducted. Indications were classified as appropriate or not appropriate according to American Society of Gastrointestinal Endoscopy (ASGE) guidelines. Endoscopic diagnoses were based on widely accepted criteria. Major complication rates were assessed.

RESULTS: A total of 20,620 patients with a mean age of 58 years were assessed, of whom 11,589 (56.2\%) were women and 9031 (43.8\%) were men. Adherence to ASGE indications led to statistically significant, clinically relevant findings. The most common indications in patients older than age 45 years of age were dyspepsia (28.5\%) and anemia (19.7\%) in the ASGE-appropriate group, and dyspepsia in patients younger than 45 years of age without therapy trial $(6.6 \%)$ in the nonappropriate group. Of the examinations, $38.57 \%$ were normal. Hiatal hernia and nonerosive gastritis were the most common findings. Important diagnoses such as malignancies and duodenal ulcers would have been missed if endoscopies were performed only according to appropriateness. There were only two major complications and no mortalities.

CONCLUSIONS: Open-access upper gastrointestinal endoscopy is a safe and effective system. More relevant findings were found when adhering to the ASGE guidelines. However, using these guidelines as the sole determining factor in whether to perform an endoscopy is not advisable because many clinically relevant diagnoses may be overlooked.

Key Words: ASGE indications; Gastroscopy findings; Gastroscopy indications; Open-access endoscopy

E ophagogastroduodenoscopy (EGD) is a widely available and relatively safe procedure (1) that is experiencing increased demand, resulting in increased costs and long wait times $(2,3)$. To overcome this, many centres are operating in an open-access (OA) approach. An OA system enables primary physicians to perform an examination without incurring the cost of previous specialist consultation, thus retaining responsibility for the patient (4). It is not a new concept, but has become increasingly popular in recent years, with increased demand worldwide (5). Studies have shown an increase in the use of OA endoscopy (OAE) in the United States and Europe $(2,6,7)$.

Similar to other units in rapidly developing countries, the workload in the endoscopy unit of the Bnai Zion Medical Center (Haifa, Israel)

\section{Un audit de neuf ans sur les endoscopies œsogastroduodénales à accès libre : Les résultats et l'expérience d'un seul centre}

HISTORIQUE : La pertinence et la sécurité de l'endoscopie à accès libre sont des enjeux très importants, car le recours à cette intervention continue d'augmenter.

OBJECTIF : Présenter une analyse d'une expérience de neuf ans sur les indications, l'efficacité diagnostique et l'innocuité de l'endoscopie œesogastroduodénale à accès libre et sur les maladies qu'elle permet de diagnostiquer.

MÉTHODOLOGIE : Série rétrospective de cas d'observation de tous les patients qui ont subi une endoscopie à accès libre entre janvier 2000 et décembre 2008. Les indications étaient classées comme pertinentes ou non selon les lignes directrices de l'American Society of Gastrointestinal Endoscopy (ASGE). Les diagnostics d'endoscopie se fondaient sur des critères largement acceptés. Les chercheurs ont évalué les taux de complications majeures.

RÉSULTATS : Au total, les chercheurs ont évalué 20620 patients d'un âge moyen de 58 ans, dont 11589 (56,2 \%) étaient des femmes et 9031 (43,8\%), des hommes. Le respect des indications de l'ASGE donnait lieu à des observations pertinentes et sur le plan clinique et statistiquement significatives. Les principales indications chez les patients de plus de 45 ans étaient la dyspepsie (28,5\%) et l'anémie (19,7\%) dans les groupes pertinents selon l'ASGE, et la dyspepsie chez les patients de 45 ans sans essai thérapeutique $(6,6 \%)$ dans le groupe non pertinent. Parmi les examens, 38,57 \% étaient normaux. La hernie hiatale et la gastrite non érosive étaient les observations les plus courantes. Des diagnostics plus graves, tels que des tumeurs malignes et des ulcères duodénaux, n'auraient pas été repérés si les endoscopies avaient été effectuées seulement selon leur pertinence. Les chercheurs ont constaté seulement deux complications majeures et aucun décès.

CONCLUSIONS: L'endoscopie œsogastroduodénale à accès libre est un système sécuritaire et efficace. Les observations étaient plus pertinentes lorsqu'on respectait les lignes directrices de l'ASGE. Cependant, il n'est pas conseillé d'utiliser ces lignes directrices comme seuls facteurs pour déterminer la pertinence d'effectuer une endoscopie, car on risque alors de rater de nombreux diagnostics pertinents sur le plan clinique.

continues to increase. This has led to concern over whether OAE was used excessively. It is a relatively safe procedure, but still involves some risk (1). Major complications are very rare and can be broken down into cardiopulmonary- , sedation- and infectious-related complications, perforation, bleeding and mortality. Investigative data regarding complication rates, specifically during diagnostic endoscopic examinations, are relatively scarce (8). Another very important issue is the appropriateness of endoscopy.

We performed a retrospective study to examine the outcome of $\mathrm{OAE}$ at the Bnai Zion Medical Center. The present study outlines the indications for OAE performed at our facility, defines the relationship of these investigations according to national practice guidelines (ie,

Gastroenterology Unit, Bnai Zion Medical Center, Technion-Institute of Technology, Haifa, Israel

Correspondence: Dr Dean Keren, Gastroenterology Unit, Bnai Zion Medical Center, 47 Golomb Avenue, Haifa 31048, Israel.

Telephone 972-4-8359426, fax 972-4-8359726, e-mail dean.keren@b-zion.org.il

Received for publication April 9, 2010. Acccepted September 15, 2010 


\section{TABLE 1}

Open-access endoscopies per year (2000 to 2008)

\begin{tabular}{lcc}
\hline Year & $\mathbf{n}$ & Total, $\%$ \\
\hline 2000 & 742 & 3.6 \\
2001 & 1476 & 7.1 \\
2002 & 1744 & 8.4 \\
2003 & 1862 & 9.0 \\
2004 & 1934 & 9.3 \\
2005 & 2481 & 12 \\
2006 & 2812 & 13.6 \\
2007 & 3438 & 16.6 \\
2008 & 4212 & 20.3 \\
Total & 20,620 & 100 \\
\hline
\end{tabular}

American Society for Gastrointestinal Endoscopy [ASGE]) and the prevalence of pathological findings. The guidelines proposed by the ASGE have been used extensively to define the appropriateness of the many indications for upper gastrointestinal endoscopy (9-11). A procedure is considered to be appropriate and worth performing if its health benefit exceeds its health risk by a sufficiently wide margin $(12,13)$. Previous OAE studies enrolled a few hundred patients, except for an Italian multicentre investigation that enrolled 6200 patients (14). In our nine-year experience, we have records of more than 20,000 cases and, therefore, aimed to investigate the appropriateness of OAE indications and the major complication rates in this considerably large number of procedures. Special emphasis was placed on attaining a relevant endoscopic diagnosis with or without the appropriate ASGE indications, and the percentage of clinically relevant diagnoses (eg, malignancies) in these groups.

\section{METHODS}

All patients who underwent $O A E$ during the nine-year period between 2000 and 2008 were included. Similar to OA systems in other medical centres, patients in this particular regional health care system are directly referred for endoscopy by their primary physicians - the cost of a previous consultation with a gastroenterologist is, therefore, eliminated. Only patients who were referred by family physicians directly to the unit were included in the present study. Patients were not known to the centre before the endoscopy and, before the procedure, underwent a clinical medical review and interview conducted by a nurse. All procedural data were computerized, with the following data collected: referring physician, patient demographics, personal medical history, indication category according to ASGE guidelines (15) based on information provided by the patient and referring physician, endoscopic findings including selection of a standard diagnosis from a predefined list and nursing records. Endoscopy was always performed regardless of its indication unless a major contraindication was present. All patients provided informed consent to the physician performing the procedure. The computer file cannot be digitally signed without the completion of all data fields; therefore, all medical records included in the present study were complete. Each complete computer file included details of the preprocedural medical interview, the endoscopy report and nursing record. The agents used for sedation were the opioid midazolam and the benzodiazepine fentanyl, administered in combination. In the past few years, the unit began using propofol-based sedation. In cases for which there was more than one endoscopic diagnosis, the most severe was used for statistical analysis. Diagnostic yield for each indication was defined as the ratio between relevant findings detected and the total number of EGDs performed for that indication.

Clinical indications were classified as appropriate or inappropriate according to the ASGE guidelines published in 2000 (9). Indications were considered to be appropriate only if they were listed among those appearing in the guidelines under the two following headings: 'EGD is generally indicated for evaluation', and 'Sequential or periodic EGD may be indicated'. Indications not included in these lists were classified as inappropriate. The diagnoses were classified as either 'clinically relevant' or 'not clinically relevant'. The clinically relevant findings were those that directly impacted therapeutic decisions and prognosis $(16,17)$. Findings that were not relevant included hiatal hernia, nonerosive gastritis and duodenitis, and others that could not be classified or had no clinical relevance according to the gastroenterologist reviewing the case. Examinations yielding normal results were also considered to be not clinically relevant.

Major complications were reviewed, and only those that required a change in medical management or an intervention (eg, further endoscopy, hospitalization and/or surgery) were identified and described. Using medications such as naloxone or flumazenil to reverse sedation was not considered to be a major complication for the purposes of the present study unless further intervention or medication changes were required. Assessments were based on the endoscopy report, hospital records and monthly follow-up reports from referring physicians.

\section{Statistical analysis}

To evaluate the association between appropriateness and the presence of clinically relevant endoscopic diagnoses, patients in whom an EGD was performed according to an ASGE indication were compared with those in whom an ASGE indication was absent. The extent of this association was expressed as the OR of finding a relevant diagnosis in patients with an appropriate indication compared with those with an inappropriate indication. The association was considered to be statistically significant if the $99 \%$ CI of the OR did not include the value 1.0. Calculation of the $99 \%$ CI was considered to be prudent because of the use of multiple tests for statistical assessments. A two-way correlation analysis between the indication and findings was performed. The extent of the association between these two variables was subsequently expressed as the OR of finding a relevant diagnosis in patients with an appropriate indication compared with those without an appropriate indication. The association was considered to be statistically significant if the $95 \% \mathrm{CI}$ of the OR did not include the value 1.0 .

The ability of the ASGE indications to forecast relevant endoscopic diagnoses was evaluated by calculating the likelihood ratio (LR) (positive and negative), both globally and for each separate indication. The LR represents a measure of the odds of having a disease relative to the previous probability of the disease. The use of LR is advantageous over sensitivity and specificity because it is less likely to change with changes in the prevalence of a disorder (18). A test is useless if the LR is equal to 1 ; a test has greater value the more the positive LR is greater than 1 and the negative LR is less than 1.

The $\chi^{2}$ test and Cramer's correlation were used to analyze statistically significant relationships in the distribution of categorical variables and relationship between indications and findings. Proportions were used in univariate and multivariate analyses, and $\mathrm{P}<0.01$ was considered to be statistically significant. The data were managed and analyzed with the Excel program (Microsoft Corporation, USA) and SPSS (IBM, USA). The study protocol was approved by the Institutional Review Board of the Bnai Zion Medical Center.

\section{RESULTS}

The study period included a total of 20,620 patients, of whom $9031(43.8 \%)$ were men and 11,589 (56.2\%) were women. The mean $( \pm \mathrm{SD})$ age of the participants was $58 \pm 17.8$ years, with men being slightly younger $(58.1 \pm 17.5$ years $)$ than the women $(59.4 \pm 18.3$ years). The data presented in Table 1 illustrate the increasing number of OAEs performed during the nine-year period.

All patients underwent standard monitoring with pulse oximetry and automated blood pressure cuff. The major complication rate was practically zero. There was one episode of transient gastrointestinal bleeding following random duodenal biopsies, a duodenal hematoma that led to hospitalization and diagnosis of a coagulation defect, and an episode of gastric perforation following argon ablation of a 
TABLE 2

Indications versus findings

\begin{tabular}{|c|c|c|c|c|c|c|c|c|}
\hline \multirow[b]{2}{*}{ Indication } & \multirow[b]{2}{*}{$\mathbf{n}$} & \multirow[b]{2}{*}{ Total (\%) } & \multicolumn{2}{|c|}{ Relevant disease, $n$} & \multirow[b]{2}{*}{ Sensitivity } & \multirow[b]{2}{*}{ Specificity } & \multicolumn{2}{|c|}{ Likelihood ratio } \\
\hline & & & With & Without & & & Positive & Negative \\
\hline Indication included in the ASGE guidelines & 17,346 & 84.1 & 4805 & 12,541 & 0.28 & 0.74 & 1.05 & 0.98 \\
\hline Abdominal pain/dyspepsia, older than 45 years of age & 5881 & 28.5 & 1202 & 4679 & 0.20 & 0.70 & 0.67 & 1.14 \\
\hline $\begin{array}{l}\text { Abdominal pain/dyspepsia, younger than } 45 \text { years of age, } \\
\text { persistent despite therapy or alarming symptom }\end{array}$ & 682 & 3.3 & 134 & 548 & 0.20 & 0.72 & 0.71 & 1.11 \\
\hline Imaging abnormality & 527 & 2.6 & 203 & 324 & 0.39 & 0.73 & 1.42 & 0.84 \\
\hline Melena or gastrointestinal blood loss investigation & 1337 & 6.5 & 734 & 603 & 0.55 & 0.74 & 2.14 & 0.61 \\
\hline Presumed chronic blood loss/anemia & 4066 & 19.7 & 867 & 3199 & 0.21 & 0.71 & 0.73 & 1.11 \\
\hline Persistent nausea or vomiting & 762 & 3.7 & 196 & 566 & 0.26 & 0.72 & 0.93 & 1.03 \\
\hline Hematemesis & 166 & 0.8 & 94 & 72 & 0.57 & 0.73 & 2.08 & 0.60 \\
\hline Heartburn and/or reflux symptoms despite therapy & 1240 & 6.0 & 285 & 955 & 0.23 & 0.72 & 0.83 & 1.07 \\
\hline Weight loss & 1036 & 5.0 & 232 & 804 & 0.22 & 0.72 & 0.81 & 1.07 \\
\hline Dysphagia or odynophagia & 716 & 3.5 & 257 & 459 & 0.36 & 0.73 & 1.32 & 0.88 \\
\hline Diarrhea (for duodenal biopsies) & 213 & 1.0 & 34 & 179 & 0.16 & 0.72 & 0.58 & 1.16 \\
\hline Follow-up or investigation for varices & 720 & 3.5 & 567 & 153 & 0.79 & 0.74 & 3.07 & 0.29 \\
\hline Indication not included in ASGE guidelines & 3274 & 15.9 & 865 & 2409 & 0.26 & 0.72 & 0.95 & 1.02 \\
\hline $\begin{array}{l}\text { Abdominal pain/dyspepsia, younger than } 45 \text { years of age } \\
\text { with no therapy trial }\end{array}$ & 1365 & 6.6 & 274 & 1091 & 0.20 & 0.72 & 0.72 & 1.11 \\
\hline Follow-up of chronic gastritis & 848 & 4.1 & 319 & 529 & 0.38 & 0.73 & 1.39 & 0.86 \\
\hline Follow-up of gastric resections & 220 & 1.0 & 83 & 137 & 0.38 & 0.73 & 1.38 & 0.86 \\
\hline Chest pain & 99 & 0.5 & 11 & 88 & 0.11 & 0.72 & 0.40 & 1.23 \\
\hline Occult blood (with normal colonoscopy) & 340 & 1.6 & 81 & 259 & 0.24 & 0.72 & 0.86 & 1.05 \\
\hline Other & 402 & 1.9 & 97 & 305 & 0.24 & 0.72 & 0.88 & 1.05 \\
\hline Total & 20,620 & 100 & 5670 & 14,950 & - & - & - & - \\
\hline
\end{tabular}

ASGE American Society for Gastrointestinal Endoscopy

gastric angiodysplasia. There were no procedure-related mortalities. No reported cases required endotracheal intubation, or resulted in death or neurological sequelae. However, there were occasional instances of respiratory depression requiring assisted ventilation. The incidence rate of respiratory events requiring bag-mask ventilation was one in 515 procedures (40 cases total). Although the endoscopy unit is in close regular contact with the referring family physicians and clinics, it was theoretically possible that delayed complications occurred and were not included in the data.

All of the indications for endoscopy are summarized in Table 2. Indications for EGD were considered to be appropriate according to ASGE criteria in $17,346(84.1 \%)$ of the cases. The main indications in this group were as follows: epigastric distress or dyspeptic symptoms in 5881 patients $(28.5 \%)$ older than 45 years of age; 4066 patients $(19.7 \%)$ were referred because of anemia; 1337 (6.5\%) were referred to investigate melena or gastrointestinal blood loss; and 1240 procedures $(6.0 \%)$ were performed to treat heartburn. The remaining 3274 (15.9\%) examinations were considered to be inappropriate. The main inappropriate indication was dyspepsia in 1365 patients $(6.6 \%)$ younger than 45 years of age without a previous therapy trial.

There were two notable indications: chest pain in 99 patients $(0.5 \%)$ and positive occult blood (with normal colonoscopy) in 340 patients $(1.6 \%)$, which led mostly to no relevant diseases.

Endoscopic findings are summarized in Table 3. Endoscopy was normal in 7954 cases (38.57\% of all endoscopies), 5670 (27.50\%) of all the procedures yielded clinically relevant findings and the remaining 14,950 (72.50\%) yielded no clinically relevant findings. The most frequent clinically relevant findings were esophagitis (977 patients [4.74\%]), esophageal varices (991 patients [4.81\%]) and gastric erosions ( 625 patients [3.03\%]). From the not clinically relevant findings, hiatal hernia accounted for $14.47 \%$ of the findings, while nonerosive gastritis accounted for $14.16 \%$.

The diagnostic yields depicted in Table 3 were higher for ASGE indications: $4805(23.30 \%)$ of the patients with clinically relevant findings had an appropriate ASGE indication compared with 865 (4.19\%) without an appropriate ASGE indication (OR 1.173 [95\% CI 1.076 to 1.278]; $\mathrm{P}<0.001$ ). When comparing indication (ie, ASGE appropriate versus inappropriate), significant, clinically relevant findings were the following: esophageal varices (OR 1.556 [95\% CI 1.271 to 1.904$]$; $\mathrm{P}<000.1$ ), esophageal ulcer (OR 0.552 [95\% CI 0.372 to 0.819]; $\mathrm{P}<0.01$ ), gastric erosions (OR 1.488 [95\% CI 1.160 to 1.910]; $\mathrm{P}<0.01$ ); and gastric polyp (OR 0.747 [95\% CI 0.606 to 0.921]; $\mathrm{P}<0.01$ ). Collective analysis of all clinically irrelevant findings yielded nonsignificant results; however, a detailed examination of the findings of a normal endoscopy (OR 0.862 [95\% CI 0.799 to 0.930]; P<0.0001) and hiatal hernia (OR 1.363 [95\% CI 1.215 to 1.530 ]; $\mathrm{P}<0.001$ ) both yielded significant results.

Serious diagnoses such as esophageal malignancy were diagnosed in 284 patients (1.38\%), of which $263(1.28 \%)$ had an appropriate ASGE indication, while only $21(0.10 \%)$ did not have an appropriate ASGE indication (OR 2.385 [95\% CI 1.53 to 3.71]; P<0001). With respect to gastric malignancy, the findings were similar: Of 440 patients (2.13\%), 392 (1.90\%) had an appropriate ASGE indication, while only $48(0.23 \%)$ did not have an appropriate ASGE indication (OR 1.554 [95\% CI 1.150 to 2.10]; $\mathrm{P}<0.01)$.

The positive and negative LRs for all ASGE indications are summarized in Table 2. As expected, the positive LR was greater than 2 for investigations of melena or hematemesis, and greater than 3 when performing esophageal varices assessment. In contrast, the positive LR was less than 1 for indications such as dyspepsia (regardless of age), heartburn, weight loss and tissue biopsies.

\section{DISCUSSION}

OAE has been growing ever since its introduction 30 years ago (19), and is likely here to stay (20). It is more accessible, cost effective and safer than an endoscopy following a previous gastroenterologist consultation. The present study analyzed a substantial number of procedures and found a very low major complication rate, which 
TABLE 3

Findings versus indications

\begin{tabular}{|c|c|c|c|c|c|c|c|}
\hline \multirow[b]{2}{*}{ Finding } & \multirow[b]{2}{*}{$\mathbf{n}$} & \multirow[b]{2}{*}{$\%$} & \multicolumn{2}{|c|}{ ASGE indication, $\mathrm{n}(\%)$} & \multirow[b]{2}{*}{ OR } & \multirow[b]{2}{*}{$95 \% \mathrm{Cl}$} & \multirow[b]{2}{*}{$\mathbf{P}$} \\
\hline & & & Yes & No & & & \\
\hline Clinically relevant & 5670 & 27.50 & $4805(23.30)$ & 865 (4.19) & 1.173 & $1.076-1.278$ & 0.000 \\
\hline Esophageal varices & 991 & 4.81 & $882(4.28)$ & $109(0.53)$ & 1.556 & $1.271-1.904$ & 0.000 \\
\hline Esophagitis & 977 & 4.74 & 844 (4.09) & $133(0.65)$ & 1.208 & $1.002-1.456$ & 0.041 \\
\hline Esophageal erosion(s) & 156 & 0.76 & $134(0.65)$ & $22(0.11)$ & 1.151 & $0.735-1.802$ & 0.660 \\
\hline Esophageal ulcer & 130 & 0.63 & $97(0.47)$ & $33(0.16)$ & 0.552 & $0.372-0.819$ & 0.003 \\
\hline Esophageal stenosis & 149 & 0.72 & $129(0.63)$ & $20(0.10)$ & 1.219 & $0.763-1.947$ & 0.499 \\
\hline Esophageal malignancy & 284 & 1.38 & $263(1.28)$ & $21(0.10)$ & 2.385 & $1.532-3.712$ & 0.000 \\
\hline Gastric ulcer & 502 & 2.43 & $423(2.05)$ & $79(0.38)$ & 1.011 & $0.793-1.288$ & 1.000 \\
\hline Gastric erosion(s) & 625 & 3.03 & $554(2.69)$ & $71(0.34)$ & 1.488 & $1.160-1.910$ & 0.001 \\
\hline Gastric malignancy & 440 & 2.13 & $392(1.90)$ & $48(0.23)$ & 1.554 & $1.150-2.100$ & 0.004 \\
\hline Gastric polyp & 564 & 2.74 & $451(2.19)$ & $113(0.55)$ & 0.747 & $0.606-0.921$ & 0.008 \\
\hline Duodenal ulcer & 612 & 2.97 & $510(2.47)$ & $102(0.49)$ & 0.942 & $0.759-1.169$ & 0.575 \\
\hline Duodenal angiodysplasia & 61 & 0.30 & $27(0.13)$ & $34(0.16)$ & 0.149 & $0.090-0.245$ & 0.000 \\
\hline Duodenal erosion(s) & 95 & 0.46 & $56(0.27)$ & $39(0.19)$ & 0.269 & $0.179-0.404$ & 0.000 \\
\hline Duodenal malignancy/polyp & 84 & 0.41 & $43(0.21)$ & $41(0.20)$ & 0.196 & $0.128-0.300$ & 0.000 \\
\hline Not clinically relevant & 14,950 & 72.50 & $12,541(60.82)$ & 2409 (11.68) & 0.937 & $0.861-1.020$ & 0.135 \\
\hline Normal & 7954 & 38.57 & $6593(31.97)$ & $1361(6.60)$ & 0.862 & $0.799-0.930$ & 0.000 \\
\hline Hiatal hernia & 2983 & 14.47 & 2607 (12.64) & $376(1.82)$ & 1.363 & $1.215-1.530$ & 0.000 \\
\hline Nonerosive gastritis & 2919 & 14.16 & $2433(11.80)$ & $486(2.36)$ & 0.936 & $0.842-1.040$ & 0.219 \\
\hline Nonerosive duodenitis & 924 & 4.48 & 756 (3.67) & $168(0.81)$ & 0.842 & $0.71-1.00$ & 0.053 \\
\hline Esophagus: Other & 63 & 0.31 & $57(0.28)$ & $6(0.03)$ & 1.796 & $0.792-4.073$ & 0.225 \\
\hline Stomach: Other & 89 & 0.43 & $79(0.38)$ & $10(0.05)$ & 1.493 & $0.781-2.854$ & 0.307 \\
\hline Duodenum: Other & 18 & 0.09 & $16(0.08)$ & $2(0.01)$ & 1.51 & $0.387-5.900$ & 0.756 \\
\hline Total & 20,620 & 100.00 & $17,346(84.12)$ & 3274 (15.88) & - & - & - \\
\hline
\end{tabular}

ASGE American Society for Gastrointestinal Endoscopy

reflected the increasing number of OAEs performed at our centre and worldwide (21). To our knowledge, this is, by far, the largest number of patients reviewed in a single study investigating the appropriateness of endoscopy.

As noted, EGD was considered to be appropriate according to ASGE criteria in $84.1 \%$ of cases. Several studies (22-25) reported a substantial rate of inappropriateness of the indication for upper endoscopy, widely ranging from $5 \%$ to $61.7 \%$. This broad variability may be, at least in part, due to the relatively low number of patients studied. Other studies show higher percentages and it clearly emphasizes the fact that general practitioners, which comprise the majority of physicians using the OA system, adhere to the ASGE guidelines. Moreover, it is an improvement over the $32 \%$ to $50 \%$ of referrals that were not ASGE appropriate reported by three studies conducted by family physicians from Europe more than 10 years ago $(9,21,26)$. We believe that one of the factors contributing to the higher rate of referrals for accepted indications in our system was a lecture series held by our physicians, which resulted in greater guideline compliance.

The efficacy or diagnostic yield of an endoscopic procedure is usually defined according to its ability to detect a finding that is potentially relevant to patient care. In our study, only $4.19 \%$ of the procedures were performed for non-ASGE indications and found to be clinically relevant. Statistical analysis of the clinically relevant findings in both groups with and without an ASGE indication yielded very significant results $(23.30 \%$ versus $4.19 \%$, respectively; $\mathrm{P}<0.001)$. Other studies $(14,27,28)$ showed that the frequency of endoscopies with positive findings that were performed for inappropriate indications range from $23 \%$ to $46 \%$; however, not all of them were statistically significant (9).

A normal endoscopic finding occurred significantly less frequently when ASGE indications were present $(\mathrm{P}<0.001)$, which emphasizes one of the primary objectives of the ASGE indications - detecting significant abnormalities. Although a normal endoscopy was categorized as a clinically irrelevant finding, it may have changed the treatment course of a patient in some instances. Naji and Brunt (29) classified upper endoscopies as being either positive or negative, and helpful or unhelpful. In this study, $67 \%$ of the procedures with normal results assisted the caring physicians. Furthermore, a negative endoscopy in dyspeptic patients significantly reduced the number of specialist consultations and lessened the burden on the medical system. Other studies (30-32) have demonstrated a better quality of life and patient satisfaction for individuals with dyspepsia and a normal endoscopy.

Regarding upper gastrointestinal malignancies, findings in the present study showed that an endoscopy leading to a diagnosis of neoplasia occurred more frequently when adhering to ASGE guidelines. This was previously documented $(16,26)$; however it contradicts the findings in the study conducted by Hassan et al (14) in 2007, who reported more malignancies in the group without an appropriate ASGE indication. From the total of 808 malignancies (284 esophageal, 440 gastric and 84 duodenal) in our study, 698 (86.38\%) were diagnosed in patients for whom the EGD was appropriate according to ASGE guidelines. In other words, if we were not 'liberal' in performing all endoscopies, except when contraindicated, 110 upper gastrointestinal malignancies would have been missed. This approach was alluded to by Shekelle et al (33) and Shekelle (34) in two wellknown articles discussing whether appropriateness criteria were ready for use in clinical practice. These reports were supportive of performing procedures that were not based solely on appropriateness criteria, and further stating that these criteria should not be the sole factor in the decision-making process.

Except for the malignancies mentioned, without that same 'liberal' policy, 102 duodenal ulcers would have been missed, thus giving additional support to our policy. 
Similar to several other studies $(9,25,26,35)$, the most common inappropriate indication was dyspepsia in patients 45 years of age or younger who received no adequate treatment and experienced no alarm symptoms. Similar indication frequencies were reported in a large American national endoscopic database (36), in which EGD was most commonly performed to evaluate dyspepsia and/or abdominal pain $(23.7 \%)$, dysphagia (20\%), symptoms of gastroesophageal reflux without dysphagia (17\%) and suspected upper gastrointestinal bleeding (16.3\%).

Endoscopic examination of the upper gastrointestinal tract in fecal occult blood test (FOBT)-positive individuals reveals mostly benign disease, with an equal prevalence in colonoscopy-negative and colonoscopy-positive patients. These types of endoscopies have a very low diagnostic yield for significant lesions, not only from a therapeutic standpoint, but also for the detection of malignant lesions (37). Our findings support what is already known - that performing routine upper endoscopy in FOBT-positive individuals is not indicated and should be undertaken only for appropriate symptoms (38), especially in patients with anemia $(39,40)$.

Our study showed that most findings were not clinically relevant when gastroscopy was performed for chest pain. The literature reports that gastroesophageal reflux disease (GERD) and dysmotility are the most frequent causes of esophageal chest pain. Additional available data regarding the prevalence of esophageal and upper gut findings in patients with noncardiac chest pain showed that a normal upper endoscopy was noted in $44.1 \%$, 28.6\% had a hiatal hernia, $19.4 \%$ had erosive esophagitis, $4.4 \%$ had Barrett's esophagus and 3.6\% had stricture/stenosis (41). We agree with the European Expert Panel who believed that endoscopy is appropriate, but not crucial, for patients with noncardiac chest pain who underwent a previous cardiac workup and whose symptoms were unresponsive to GERD treatment. Conversely, in the absence of a previous cardiac workup, endoscopy is inappropriate (42).

\section{Study limitations}

Indications for OAE were based on information provided from the referral forms; consequently, appropriateness was possibly underestimated. Furthermore, we did not include histological analysis of normal mucosa, which could lead to a diagnosis of celiac disease and, therefore, clinical relevance.

Appendix 1 of the ASGE guidelines (43) provides examples (ie, including, but not limited to) of acceptable indications for OAE. For gastroscopy, they included the following: dyspepsia that is poorly responsive to proton pump inhibitor trial, chronic GERD to rule out Barrett's esophagus and positive guaic-based FOBT (for patients with negative colonoscopy results).

Major complication rates were extremely low. However, despite our regular meetings and monthly follow-up reports, it is theoretically possible that delayed complications occurred and were not reported to us by the referring physicians and, therefore, not included in our data. The two complications documented in the present study concur with those reported in previous studies $(44,45)$. The low incidence rate of respiratory depression of slightly below one in 500 procedures documented in the present study was comparable with incidence rates reported in the literature. Reports from nonanaesthesia endoscopy specialists working in three separate centres documented incidence rates of respiratory events requiring bag-mask ventilation that ranged from slightly below one in 500 to slightly below one in 1000 cases (46).

\section{CONCLUSION}

We reported our substantial experience with more than 20,000 endoscopic procedures referred to us in an OA manner over a nine-year period. As shown, this referral system is growing annually. It is more efficient, less costly and safer than endoscopy requiring previous consultation. Education programs for the referring physicians must be implemented to maximize the potential of this system to assist them in providing proper medical care before and after the procedure.
The results show that the ASGE guidelines are a good tool to enable the comparison of different centres with respect to procedure results and indications. However, using these guidelines as the sole determinant for performing endoscopies is not advisable because many clinically relevant diagnoses may be overlooked. Successful implementation of an $\mathrm{OA}$ system requires ongoing assistance to the general practitioners as to the appropriate indications for gastrointestinal endoscopy.

\section{KEY RESULTS AND MESSAGES}

- Single-centre, nine-year experience with more than 20,000 OAE procedures.

- $\mathrm{OAE}$ is a very safe, much less expensive and less timeconsuming system.

- The most common indications in the ASGE-appropriate group were dyspepsia in patients older than 45 years of age and in those with anemia.

- The most common indication in the non-ASGE-appropriate group was dyspepsia in patients younger than 45 years of age who had not previously undergone a therapy trial.

- The most common findings were hiatal hernia and nonerosive gastritis.

- Strict adherence to the ASGE guidelines would have missed many malignancies and duodenal ulcers.

- We suggest a 'liberal' policy in performing all open-access upper gastrointestinal endoscopies unless a contraindication is present.

- We stress the importance of close, regular contact between the OAE unit and referring family physicians.

\section{REFERENCES}

1. Quine MA, Bell GD, McCloy RF, Charlton JE, Devlin HB, Hopkins A. Prospective audit of upper gastrointestinal endoscopy in two regions of England: Safety, staffing, and sedation methods. Gut 1995;36:462-7.

2. Marshall JB. Open access endoscopy in Britain: A service in evolution. Gastrointest Endosc 1998;48:653-8.

3. Scott B. Endoscopic demands in the 90's. Gut 1990;31:125-6.

4. American Society for Gastrointestinal Endoscopy (ASGE): Open access endoscopy. Gastrointest Endosc 2002;56:793-5.

5. British Society of Gastroenterology. Provision of gastrointestinal endoscopy and related services for a district general hospital. London: BSG, 1990.

6. Mahajan RJ, Marshall JB. Prevalence of open-access gastrointestinal endoscopy in the United States. Gastrointest Endosc 1997;46:21-6.

7. Silcock JG, Bramble MG. Open access gastroscopy: Second survey of current practice in the United Kingdom. Gut 1997;40:192-5.

8. Eisen GM, Baron TH, Dominitz JA, et al. Complications of upper GI endoscopy. American Society for Gastrointestinal Endoscopy. Gastrointest Endosc 2002;55:784-93.

9. American Society for Gastrointestinal Endoscopy. Appropriate use of gastrointestinal endoscopy. Gastrointest Endosc 2000;52:831-7.

10. Gonvers JJ, Burnand B, Froehlich F, et al. Appropriateness and diagnostic yield of upper gastrointestinal endoscopy in an open-access endoscopy unit. Endoscopy 1996;28:661-6.

11. Charles RJ, Chak A, Cooper GS, et al. Use of open access in GI endoscopy at an academic medical center. Gastrointest Endosc 1999;50:480-5.

12. Brook RH, Chassin MR, Fink A, et al. A method for the detailed assessment of the appropriateness of medical technologies. Int J Tech Assess Health Care 1986;2:53-64.

13. Park RE, Fink A, Brook RH. Physician ratings of appropriate indications for six medical and surgical procedures. Am J Public Health 1986;76:766-72.

14. Hassan C, Bersani G, Buri L, et al. Appropriateness of upper-GI endoscopy: An Italian survey on behalf of the Italian Society of Digestive Endoscopy. Gastrointest Endosc 2007;65:767-74. 
15. Rossi A, Bersani G, Ricci G, et al. ASGE guidelines for the appropriate use of upper endoscopy: Association with endoscopic findings. Gastrointest Endosc 2002;56:714-9

16. Adang RP, Vismans FJ, Talmon JL, Hasman A, Ambergen A, Stockbruger W. Appropriateness of indications for diagnostic upper gastrointestinal endoscopy: Association with relevant endoscopic disease. Gastrointest Endosc 1995:42:390-7.

17. Frohelich F, Repond C, Mullhaupt B, et al. Is the diagnostic yields of upper GI endoscopy improved by the use of explicit panel-based appropriateness criteria? Gastrointest Endosc 2000:52:333-41.

18. Suchman AL, Dolan JG. Odds and likelihood ratios. In: Panzer RJ, Black ER, Griner PF, eds. Diagnostic Strategies for Common Medical Problems. Philadelphia: American College of Physicians, 1991:29-34.

19. Holdstock G, Wiseman M, Loehry CA. Open access endoscopy service for general practitioners. BMJ 1979;1:457-9.

20. British Society of Gastroenterology. Provision of gastrointestinal endoscopy and related services for a district general hospital. London: BSG; 1990.

21. Charles RJ, Cooper GS, Wong RC, Sivak MV Jr, Chak A. Effectiveness of open-access endoscopy in routine primary-care practice. Gastrointest Endosc 2003;57:183-6.

22. Froehlich F, Burnand B, Pache I, et al. Overuse of upper gastrointestinal endoscopy in a country with open-access endoscopy: A prospective study in primary care. Gastrointest Endosc 1997;45:13-9.

23. Chan YM, Goh KL. Appropriateness and diagnostic yield of EGD: A prospective study in a large Asian hospital. Gastrointest Endosc 2004;59:517-24.

24. Mahajan RJ, Barthel JS, Marshall JB. Appropriateness of referrals for open-access endoscopy. How do physicians in different medical specialties do? Arch Intern Med 1996;156:2065-9.

25. Trevisani L, Sartori S, Gilli G, et al. Appropriateness of upper gastrointestinal endoscopy: A hospital-based study. Dig Dis Sci 2001;46:2695-9.

26. Minoli G, Prada A, Gambetta G, et al. The ASGE guidelines for the appropriate use of upper gastrointestinal endoscopy in an open access system. Gastrointest Endosc 1995;42:387-9.

27. Holdstock G, Wiseman M, Loehry CA. Open access endoscopy service for GPs. Br Med J 1979;1:457-9.

28. Trevisani L, Sartori S, Gilli G, et al. Appropriateness of upper gastrointestinal endoscopy: A hospital-based study. Dig Dis Sci 2001;46:2695-9.

29. Naji SA, Brunt PW. Improving the selection of patients for upper gastrointestinal endoscopy. Gut 1993;34:187-91.

30. Wiklund I, Glise H, Jerndal P, Carlsson J. Does endoscopy have a positive impact on quality of life in dyspepsia? Gastrointest Endosc 1998;47:449-54.

31. Lucock MP, Morley S, White C. Response of consecutive patients to reassurance after gastroscopy: Results of self administered questionnaire survey. Br Med J 1997;315:572-5.
32. Rabeneck L, Wristers K. Impact of upper endoscopy on satisfaction in patients with previously uninvestigated dyspepsia. Gastrointest Endosc 2003;57:295-9.

33. Shekelle PG, Hahan JK, Bernstein SJ, Leape LL, Kamber CJ, Park RE. The reproducibility of a method to identify the overuse and underuse of medical procedures. N Engl J Med 1998;338:188-95.

34. Shekelle PG. Are appropriateness criteria ready for use in clinical practice? N Engl J Med 2001;344:677-8.

35. Zuccaro G, Provencher K. Does an open access system properly utilize endoscopic resources? Gastrointest Endosc 1997;46:15-20.

36. Lieberman DA, De Garmo PL, Fleischer DE, Eisen GM, Helfand M. Patterns of endoscopy use in the United States. Gastroenterology 2000;118:619-24.

37. Chen YK, Gladden DR, Kestenbaum DJ, Collen MJ. Is there a role for upper gastrointestinal endoscopy in the evaluation of patients with occult blood-positive stool and negative colonoscopy? Am J Gastroenterol 1993;88:2026-9.

38. Hisamuddin K, Mowat NA, Phull PS. Endoscopic findings in the upper gastrointestinal tract of faecal occult blood-positive, colonoscopy-negative patients. Dig Liver Dis 2006;38:503-7.

39. Bini EJ, Rajapaksa RC, Valdes MT, Weinshel EH. Is upper gastrointestinal endoscopy indicated in asymptomatic patients with a positive fecal occult blood test and negative colonoscopy? Am J Med 1999;106:613-8.

40. McLoughlin MT, Telford JJ. Positive occult blood and negative colonoscopy - should we perform gastroscopy? Can J Gastroenterol 2007;21:633-6.

41. Dickman R, Mattek N, Holub J, Peters D, Fass R. Prevalence of upper gastrointestinal tract findings in patients with noncardiac chest pain versus those with gastroesophageal reflux disease (GERD)-related symptoms: Results from a national endoscopic database. Am J Gastroenterol 2007;102:1173-9.

42. Vader J P, Larequi-Lauber T, Froehlich F, Burnand B, Dubois RW, Gonvers JJ. Appropriateness of gastroscopy: Atypical chest pain. Endoscopy 1999;31:611-4.

43. Eisen GM, Baron TH, Dominitz JA. Open access endoscopy. Gastrointest Endosc 2002;56:793-5; < http://www.asge.org/ PublicationsProductsIndex.aspx?id=352> (Accesed on December 17, 2010).

44. Hernandez LV, Jacobson JW, Harris MS. Comparison among the perforation rates of Maloney, balloon, and Savary dilation of esophageal strictures. Gastrointest Endosc 2000;51(4 pt 1):460-2. (Erratum in Gastrointest Endosc 2003;58:642).

45. Wolfsen HC, Hemminger LL, Achem SR, et al. Complications of endoscopy of the upper gastrointestinal tract: A single-center experience. Mayo Clin Proc 2004;79:1264-7.

46. Rex DK, Heuss LT, Walker JA, Qi R. Trained registered nurses/endoscopy teams can administer propofol safely for endoscopy. Gastroenterology 2005;129:1384-91. 


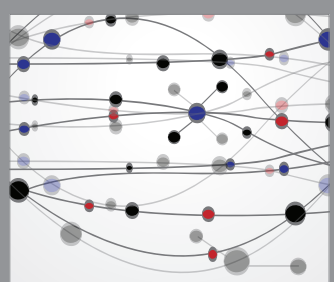

The Scientific World Journal
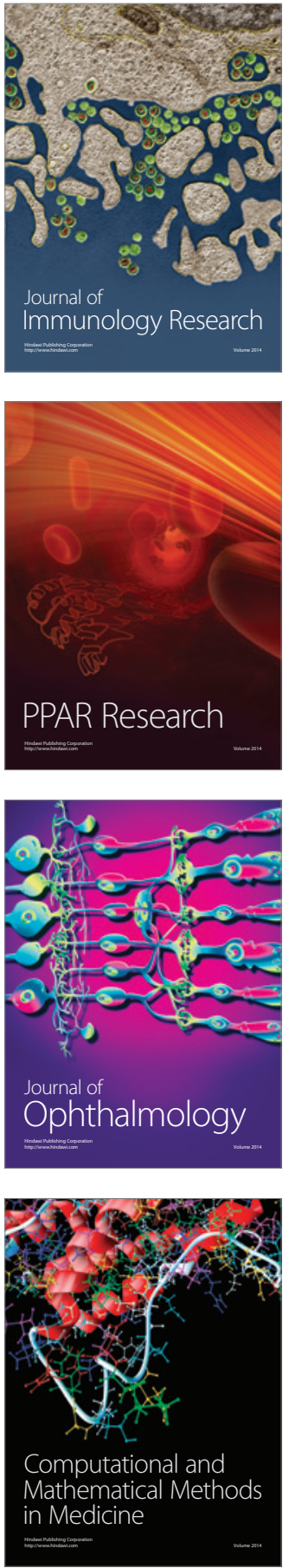

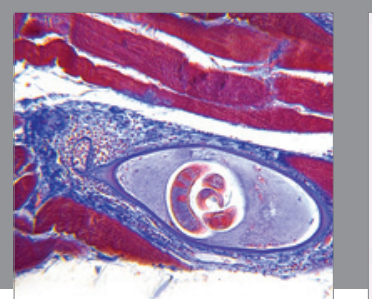

Gastroenterology Research and Practice

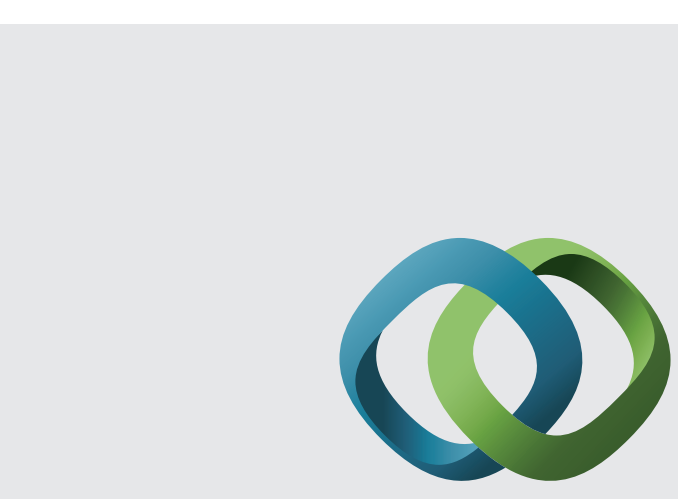

\section{Hindawi}

Submit your manuscripts at

http://www.hindawi.com
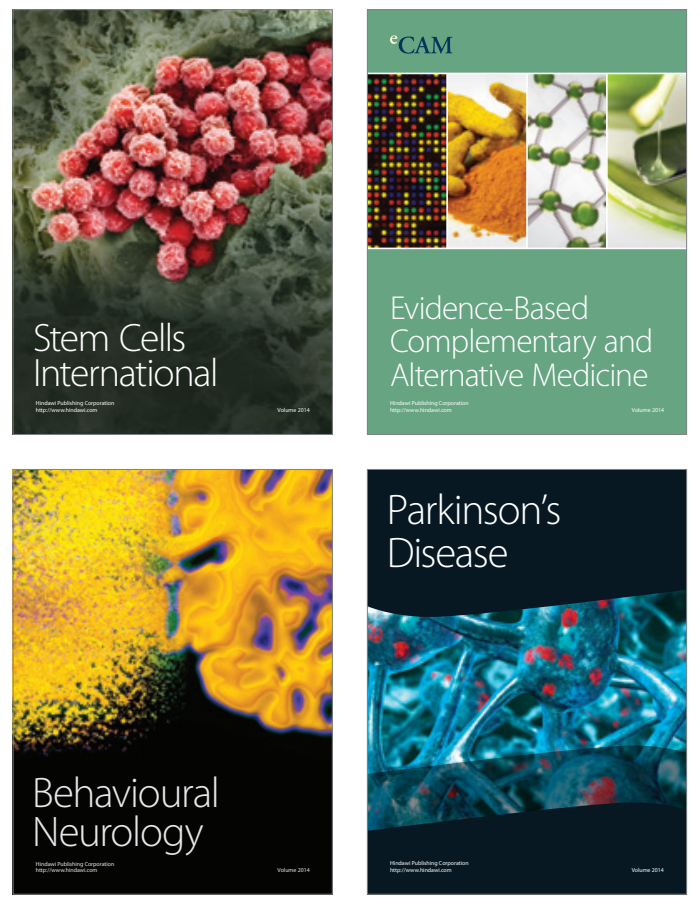
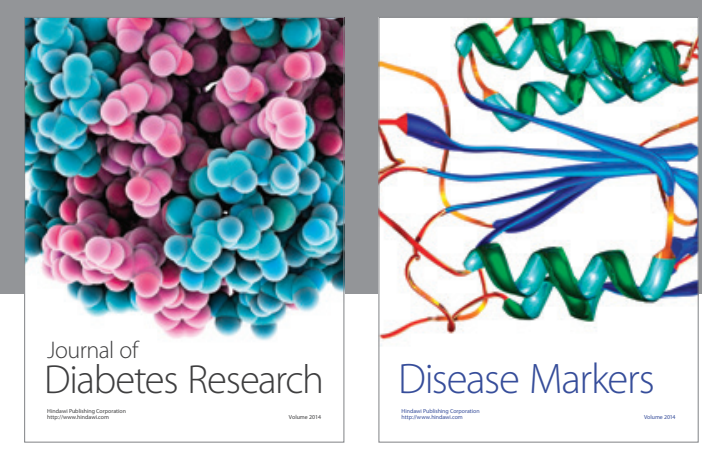

Disease Markers
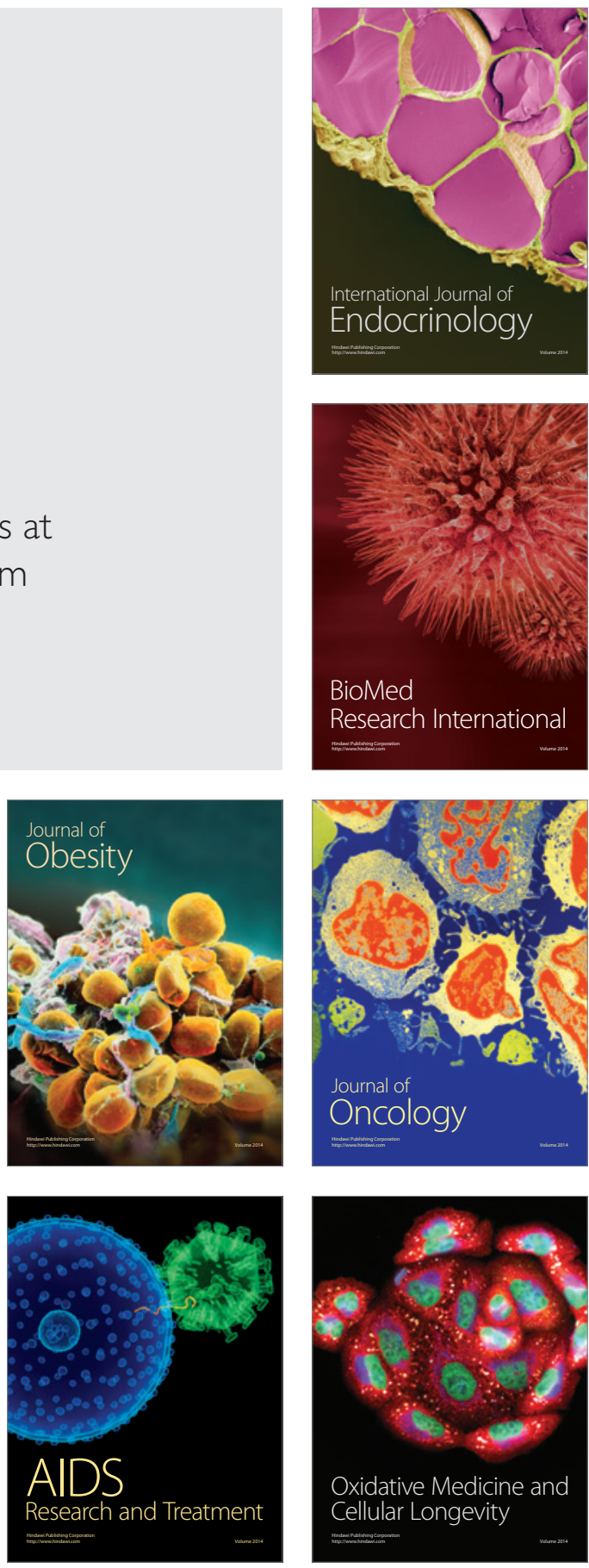